\title{
On the Position of Genital Pores in a Sea Spider, Austrodecus tubiferum (Pycnogonida, Austrodecidae)
}

\author{
$\operatorname{AUTHOR}(\mathrm{S})$ :
}

Miyazaki, Katsumi

\section{CITATION:}

Miyazaki, Katsumi. On the Position of Genital Pores in a Sea Spider, Austrodecus tubiferum (Pycnogonida, Austrodecidae). PUBLICATIONS OF THE SETO MARINE BIOLOGICAL LABORATORY 2004, 40(1-2): 107-111

ISSUE DATE:

2004-07-31

URL:

http://hdl.handle.net/2433/176315

RIGHT: 


\title{
On the Position of Genital Pores in a Sea Spider, Austrodecus tubiferum (Pycnogonida, Austrodecidae)
}

\author{
KATSUMI MiYAZAKI
}

\author{
Seto Marine Biological Laboratory, Field Science Education and Research Center, Kyoto \\ University, Shirahama, Wakayama 649-2211, Japan
}

\begin{abstract}
The so-called genital pores of both females and males in a pycnogonid, Austrodecus tubiferum are observed by scanning electron microscopy. The position of the male genital pore of this species has been previously described as being in a different location than the pores of most other pycnogonids, but the present observation demonstrates that the previously described "male genital pore" is just a subcuticular structure, and the actual male genital pores in this species are located in the normal position, on the ventral surface of the second coxal segment. Female genital pores are located also in the normal position.
\end{abstract}

Key words: Pycnogonida, Austrodecus tubiferum, genital pore, SEM

\section{Introduction}

In most pycnogonids, the position of the genital pores is stably located on the "second coxae" of the walking legs in both females and males, but some exceptions have been reported from males of species in the two families, the Rhynchothoracidae and the Austrodecidae. In Rhynchothoracidae, Rhynchothorax mediterraneus and $R$. percivali were said to have their male genital pores on the "third coxae" of the third pair of walking legs (Clark, 1976; Child, 1988). The scanning electron microscopic observation on the former species, however, showed that the "pores" were the openings of the cement glands of males, and the probable real genital pores were on the second coxae of the fourth pair of legs (Miyazaki, 1996). Another exception was reported for Austrodecus tubiferum (Austrodecidae). Stock (1957) wrote that the male genital pores of this species were "as far as I was able to ascertain, on the ventral surface of the third coxae of all legs" (italics by the original author), but he did not show any pore-like structures in the figures. No other authors have mentioned the position of the genital pores of either male or female A. tubiferum.

In the present study, the "genital pores" in Austrodecus tubiferum are observed with scanning electron microscopy (SEM) in order to determine their true location.

\section{Materials and Methods}

Some specimens of Austrodecus tubiferum Stock, 1957 were collected from Tanabe Bay in the Kii Peninsula by Dr. Atsushi Mori taken from wastes of hauls of spiny lobster fishing off Minabe (depth unknown) in the winter seasons from 1993 to 1999. From Japanese waters, this species has been recorded in Sagami Bay and Okinawa (Stock, 1957; Nakamura and Child, 1988, 1991), and this is the first record from Tanabe Bay. In total, 4 female, 11 male, and 8 juvenile specimens were kindly transferred to the author in live or fixed (with formalin or $70 \%$ ethanol) condition. Live or formalinfixed specimens were put into an alcoholic fixative "Kryofix" (Merck Co.) for several days, and then kept in $70 \%$ ethanol.

After a short ultrasonic treatment for cleaning, some specimens were observed under a light microscope. Other cleaned specimens for SEM were dehydrated with a graded ethanol series, transferred into absolute $t$-butanol for three changes, and then placed in a refrigerator $\left(4^{\circ} \mathrm{C}\right)$. The frozen specimens were processed in a freeze drier, Hitachi ES-2030. The dried specimens were mounted on a stub, coated with Pt-Pd, and observed with a scanning electron microscope, Hitachi S4300 at $10 \mathrm{kV}$. 


\section{Results}

Males

A distinct pore-like structure located on the ventral surface of the third coxa of every walking leg can be seen with light microscopy (Fig. 1) in the area where Stock (1957) thought he observed the genital pore, but no openings can be seen in that region with the SEM (Fig. 2). The SEM does reveal, however, a slit on the ventral surface of the second coxa of the fourth pair of walking legs only (Fig. 2). The slit is lunulate-shaped and located on a low conical process (Fig. 3) and its size is too small to detect the structure with light microscopy.

\section{Females}

In females, a distinct pore with a lid is located on the ventral surface of the second coxa of every walking leg (Fig. 4). The size of the pore is large enough to be detected with light microscopy.

\section{Discussion}

In most pycnogonids, the male genital pores are lunulate-shaped openings located on the second coxae of all or some pairs of walking legs (King, 1973; Arnaud and Bamber, 1987). The shape and position of the slits found with the SEM in the present study (Fig. 2) strongly suggest that they are the real male genital pores in A. tubiferum. The pore-like structure on the ventral surface of the third coxa was visible with light microscopy but not with SEM, and thus it has a subcuticular nature. It is quite possible that this is the structure which Stock (1957) mistook for the male genital pore. The shape and position of the pore found on the second coxal segment of the female A. tubiferum (Fig. 4) is concordant with those of female genital pores described for most other pycnogonid species.

The present conclusion for the position of the male genital pores in A. tubiferum is similar to that

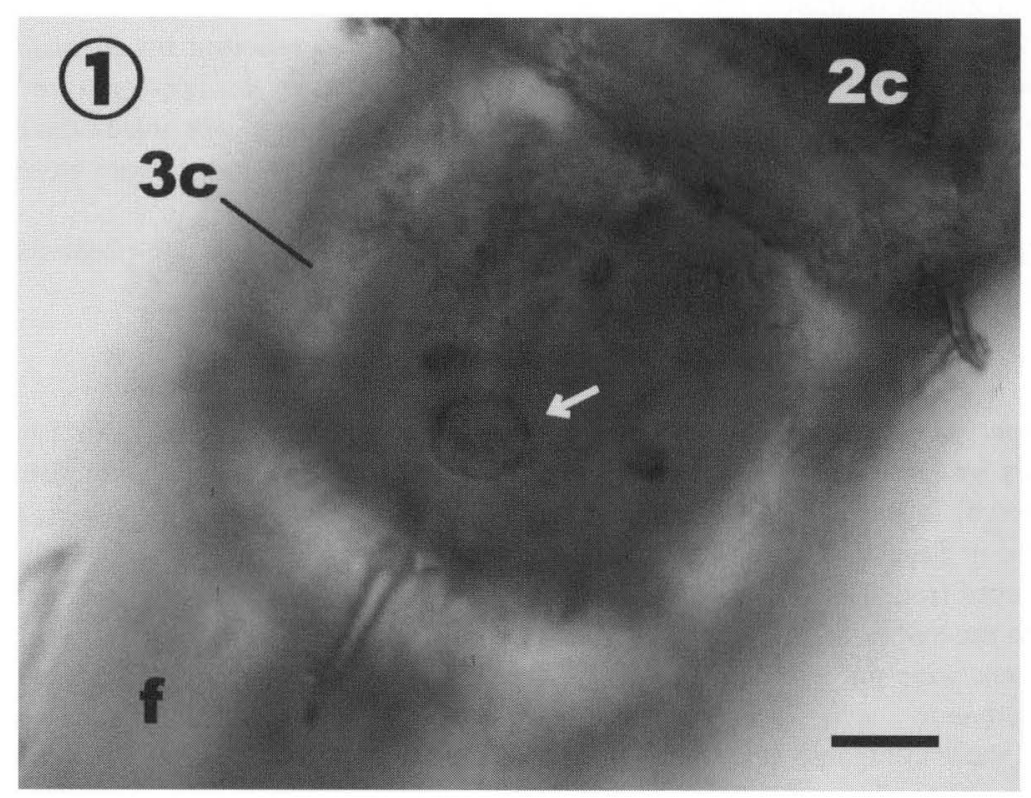

Fig. 1. Ventral surface of third coxa of fourth right walking leg in a male Austrodecus tubiferum. Note the distinct pore-like structure (arrow). Light microscopy. Bar $=25 \mu \mathrm{m}$. f: femur, $2 \mathrm{c}$ : second coxa, $3 \mathrm{c}$ : third coxa. 


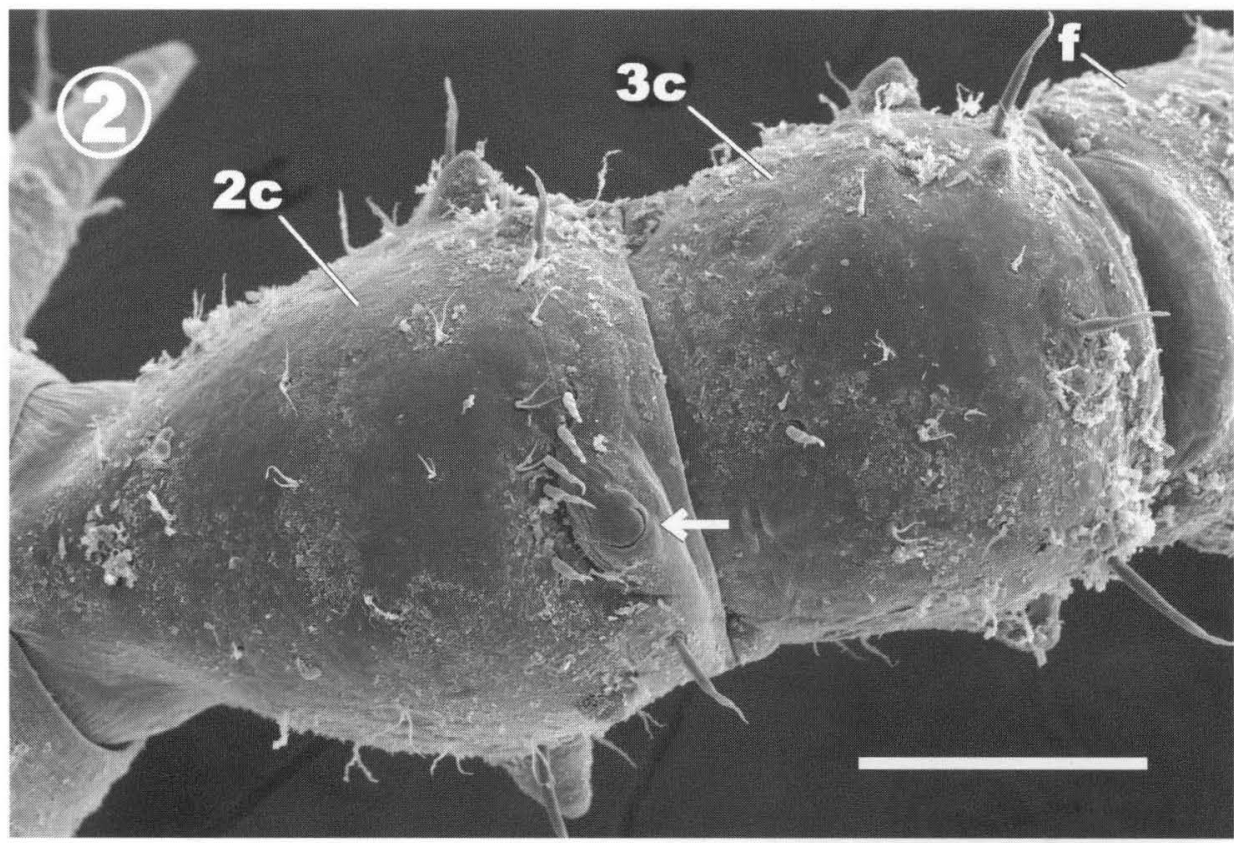

Fig. 2. Ventral surface of second and third coxae of fourth left walking leg in a male. Arrow indicates the lunulate-shaped slit which is presumably the real male genital pore. SEM. Bar $=50 \mu \mathrm{m}$. f: femur, $2 \mathrm{c}$ : second coxa, $3 \mathrm{c}$ : third coxa.

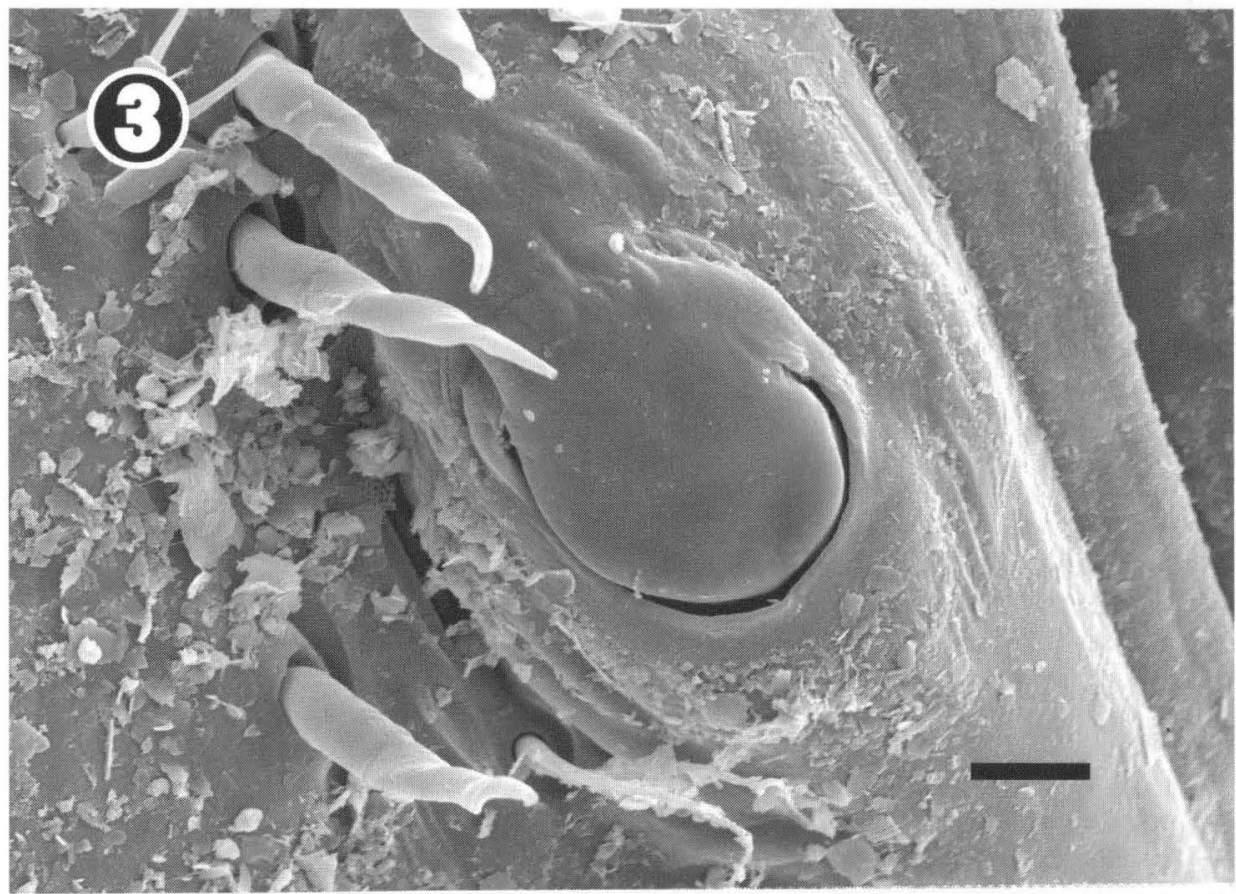

Fig. 3. Enlargement of the lunulate-shaped slit shown in Fig. 2. SEM. Bar $=5 \mu \mathrm{m}$. 


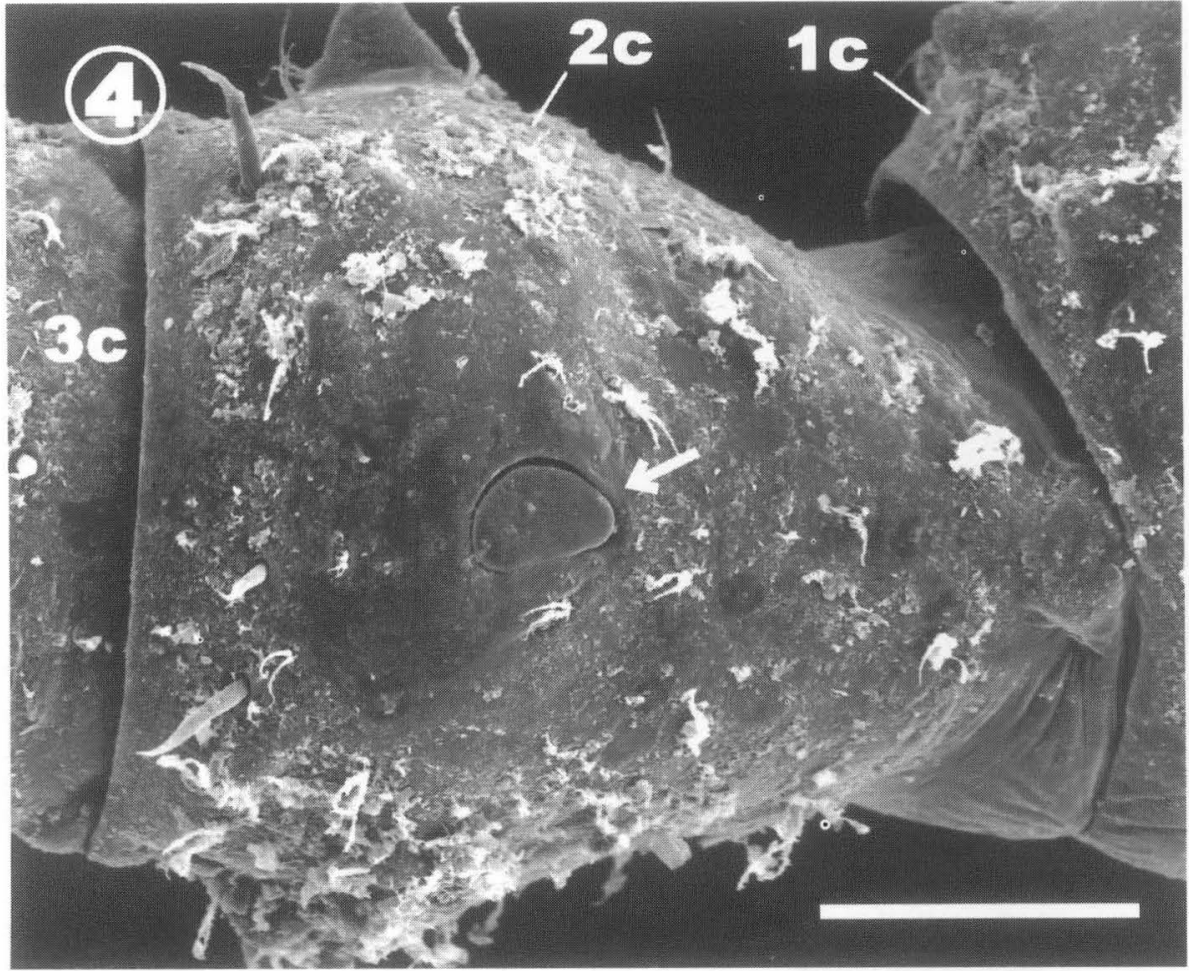

Fig. 4. Ventral surface of second coxa of fourth right walking leg in a female Austrodecus tubiferum. Arrow indicates the genital pore and lid. SEM. Bar $=50 \mu \mathrm{m}$. $1 \mathrm{c}-3 \mathrm{c}$ : first to third coxae.

for Rhynchothorax mediterraneus (Miyazaki, 1996). Both species are very tiny (trunk length is about $1 \mathrm{~mm}$ ), and the details of some of the smaller parts such as the male genital pores are difficult to observe with light microscopy. Thus, the use of the scanning electron microscope to reveal more structural details in these cases is very important in order to provide the most accurate description possible of these very tiny species. Also, histological examination will be necessary in order to confirm the true nature of the structures discussed in the present study.

\section{Acknowledgements}

The author wishes to dedicate the present paper to the late Professor Emeritus J. H. Stock, University of Amsterdam who helped in the identification of the present materials and gave a continuous encouragement to him. Special thanks are due to Dr. A. Mori, Marine Biological Research Institute of Japan Co. Ltd., for his kind transfer of materials for the present study, and to Dr. B. A. Bain, Monash University, Australia, for her useful comments on the earlier version of the manuscript. The present study was partly supported by a Grant-in-Aid for Scientific Research from the Japan Society for the Promotion of Science.

\section{References}

Arnaud, F. and Bamber, R. N. 1987. The Biology of Pycnogonida. Advances in Marine Biology, 24, 1-96.

Child, C. A. 1988. Pycnogonida of the western Pacific islands, III: Recent Smithsonian-Philippine expeditions. Smithsonian Contributions to Zoology, 468, 1-32.

Clark, W. C. 1976. The genus Rhynchothorax Costa (Pycnogonida) in New Zealand waters. Journal of the Royal 
Society of New Zealand, 6, 287-296.

King, P. E. 1973. Pycnogonids. Hutchinson, London, 144 pp.

Miyazaki, K. 1996. Scanning electron microscopic observations on the so-called "male genital pore" in the pycnogonid, Rhynchothorax mediterraneus (Pycnogonida: Rhynchothoracidae). Proceedings of Arthropodan Embryological Society of Japan, 31, 1-3.

Nakamura, K. and Child, C. A. 1988. Pycnogonida of the western Pacific islands IV. On some species from the Ryukyu Islands. Proceedings of the Biological Society of Washington, 101, 662-670.

Nakamura, K. and Child, C. A. 1991. Pycnogonida from waters adjacent to Japan. Smithsonian Contributions to Zoology, 512, 1-74.

Stock, J. H. 1957. The pycnogonid family Austrodecidae. Beaufortia, 6, 1-81. 